\title{
Yoga Therapy in Children with Cystic Fibrosis Decreases Immediate Anxiety and Joint Pain
}

\author{
Christopher McNamara, ${ }^{1}$ Mahrya Johnson, ${ }^{2}$ Lisa Read, ${ }^{2}$ Heidi Vander Velden, \\ Megan Thygeson, ${ }^{2}$ Meixia Liu, ${ }^{2}$ Laura Gandrud, ${ }^{2}$ and John McNamaraa ${ }^{1,2,3}$ \\ ${ }^{1}$ Children's Respiratory and Critical Care Specialists, PA, Minneapolis, MN, USA \\ ${ }^{2}$ Children's Hospitals and Clinics of Minnesota, Minneapolis, MN, USA \\ ${ }^{3}$ Department of Pediatrics, University of Minnesota, Minneapolis, MN, USA \\ Correspondence should be addressed to John McNamara; john.mcnamara@childrensmn.org
}

Received 27 May 2016; Revised 12 October 2016; Accepted 21 November 2016

Academic Editor: Crystal L. Park

Copyright (C) 2016 Christopher McNamara et al. This is an open access article distributed under the Creative Commons Attribution License, which permits unrestricted use, distribution, and reproduction in any medium, provided the original work is properly cited.

\begin{abstract}
This study was designed to determine whether yoga might alleviate symptoms of pain, sleep disturbance, anxiety, and depression in children with cystic fibrosis (CF). CF is the most common genetic, life-limiting chronic disease among Caucasian populations. It primarily affects the lungs but also many other secretory organs and consequently leads to significant morbidities. Research has shown that children with CF have significantly increased depression, anxiety, and pain compared to their healthy counterparts. Subjects participated in six one-on-one sessions over a 10-week period with a certified instructor who designed each yoga practice based on a preestablished list of 30 yoga asanas. Questionnaires evaluating pain, sleep disturbance, sustained anxiety, immediate anxiety, and depression were administered. Differences between premeasures and postmeasures were evaluated using a two-sided test. Twenty subjects were assessed (12 females/8 males), median age of 11 (7-20) years. Mean immediate anxiety scores decreased (before session to after session 29 to 23.6, respectively, $p<0.001$ ). Joint pain improved (3.25 to 3.65, $p=0.028$ ). CFQ-R emotion subscale improved from 79.2 to 85 ( $p=0.073)$, and the respiratory subscale improved from 66.7 to $79.2(p=0.076)$. Other results were less notable. We conclude that yoga may reduce immediate anxiety and joint pain in patients with CF.
\end{abstract}

\section{Introduction}

Cystic fibrosis (CF) is the most common genetic, life-limiting, chronic, multiorgan disease among Caucasian populations affecting approximately 30,000 children in the United States and 70,000 worldwide [1,2]. Although recent advances in diagnosis and treatment have led to increases in lifespan, $\mathrm{CF}$ remains one of the most difficult chronic conditions to manage $[3,4]$ and patients with CF suffer from declining health-related quality of life as the disease progresses [5, 6]. Studies have shown that children with CF experience symptoms of pain, sleep disturbance, anxiety, and depression [7-19].

There is evidence in healthy populations that poor sleep is associated with negative behavior and decreased school performance [20,21]. Cavanaugh et al. measured sleep quality in fifty subjects with CF (age 6-19 years) using actigraphy.
Forty-two participants (84\%) experienced poor sleep which was associated with worsening attention and attitude functioning [19]. In addition, there may be an association between decline in pulmonary function and sleep disruption [22] ultimately impacting quality of life for individuals with $\mathrm{CF}$ [14].

Anxiety and depression are well-recognized correlates of chronic illness [23-26] and have become an increasing concern in the CF community $[4,10]$. These factors may contribute to decreased quality of life as well as decreased adherence to treatments $[3,4,10,27]$. A meta-analysis evaluating 31 studies and 18,245 subjects with a variety of chronic health diseases revealed subjects with depression were 1.76 times more likely to be nonadherent to their treatment regimens [26].

As other secondary health conditions are increasingly identified in patients with $\mathrm{CF}$, it is important to identify 
TABLE 1: Study schema: timing intervals of yoga sessions, questionnaire administration.

\begin{tabular}{|c|c|c|c|c|c|c|c|c|}
\hline & Week & Week & Week & Week & Week & Week & Week & $\overline{\text { Week }}$ \\
\hline & 1 & 2 & 3 & 4 & 5 & $6-10^{*}$ & +1 & +2 \\
\hline Yoga session & $\mathrm{X}$ & $\mathrm{X}$ & $\mathrm{X}$ & $\mathrm{X}$ & $\mathrm{X}$ & $\mathrm{X}$ & & \multirow{3}{*}{$\mathrm{X}$} \\
\hline \multirow{2}{*}{ STAIC } & Before & Before & Before & Before & Before & Before & & \\
\hline & After & After & After & After & After & After & & \\
\hline CFQ-R & $\mathrm{X}$ & & & & & & & $\mathrm{X}$ \\
\hline MSAS & $\mathrm{X}$ & & & & & & & $\mathrm{X}$ \\
\hline HADS & $\mathrm{X}$ & & & & & & & $\mathrm{X}$ \\
\hline CES-DC & $\mathrm{X}$ & & & & & & & $\mathrm{X}$ \\
\hline APSA & $\mathrm{X}$ & & & & & & & $\mathrm{X}$ \\
\hline
\end{tabular}

* Participants were allowed 10 weeks to complete 6 therapeutic yoga sessions.

(i) Before: test administered immediately prior to yoga session.

(ii) After: test administered immediately after yoga session.

(iii) $\mathrm{X}$ indicates the week a test was conducted.

and treat these issues in order to improve quality of life and treatment adherence. Complementary therapy offers a variety of symptom management techniques and may be particularly beneficial for those patients who deal with a complex chronic disease treatment regimen. A study, conducted in subjects with $\mathrm{CF}$, assessed the prevalence of complementary or alternative therapy and demonstrated that $75 \%$ of subjects used at least one method of complementary/alternative therapy and described it as being helpful [28].

Yoga has become an increasingly popular complementary therapy to improve and maintain health and well-being. A growing body of research suggests that yoga has significant psychophysiological benefits and clinical relevance as a complementary therapeutic practice [29]. People who participate in yoga may benefit from improved muscle strength, flexibility, blood circulation, oxygen uptake, and hormone function [30]. Research suggests benefits of yoga for various diseases including respiratory disorders, cancers, rheumatoid arthritis, autism spectrum disorder, depression, obesity, diabetes, end stage renal disease, hemophilia, and gastrointestinal disorders [31-55]. Furthermore, it has been shown to improve psychological outcomes in adults with chronic obstructive pulmonary disease [56]. These findings extend to pediatric populations [42-48]. Similarly, evidence supports the efficacy of yoga in adults and children with asthma, showing improvements in quality of life, and, in some cases, improvement in pulmonary function and biochemical profiles, although more high quality research is needed [5761].

These results set the stage for this study and the goal to explore the possible benefits of yoga in decreasing/alleviating symptoms of pain, sleep disturbance, anxiety, and depression and improving quality of life in children with cystic fibrosis.

\section{Materials and Methods}

2.1. Subjects. Subjects were eligible if they were between the ages of 7 and 21 years; had a diagnosis of CF; had no medical contraindications at the time of participation such as advanced liver disease, organ transplant, or severe pulmonary exacerbation; had no participation in an investigational treatment study within 30 days of enrollment; and were not participating in any other yoga practice. Subjects were recruited over the phone or at a clinic visit from both Children's Hospitals and Clinics of Minnesota and University of Minnesota. Subjects were enrolled after obtaining informed consent. The Institutional Review Board of Children's Hospitals and Clinics of Minnesota, Minneapolis, Minnesota, approved this study.

2.2. Yoga Certified Instructors and Training. Four certified yoga instructors were selected based on experience with yoga, pediatrics, and chronic disease. Each instructor had a minimum of 200 hours of yoga teacher training from certified yoga alliance schools such as Core Power and Atmananda Yoga Studio. Instructors participated in a two-day training for this study that included CF disease information, consistent use of preselected asanas (postures), administration of questionnaires, session planning/logistics, patient interaction/communication, and the facility/environment.

2.3. Intervention. Each subject participated in six private (one-on-one) yoga sessions over a ten-week period. Table 1 describes the timing intervals of the yoga sessions. Parents were asked to remain in the waiting room during each session. Sessions were spaced at least seven days apart. The ten-week period was selected to allow for flexibility with family schedules. Sessions were one hour in length and included 40 minutes of yoga practice with 10 minutes before and after the intervention to complete questionnaires and discuss the session activities. The same location/room was used for all sessions to reduce possible environmental influences.

To establish standardization, a preestablished list of 30 asanas and associated modifications were selected specifically for this study by the investigators who have also had yoga instructor experience. Each subject's yoga practice was designed from the preestablished list according to their energy levels, attitudes, physical limitations, and competencies on the day of the session. To maximize the impact of 
each session, instructors were allowed to adjust the patient's practice within the preestablished list as needed. Because yoga typically allows for individualization of this nature, it was viewed as a potentially effective intervention due to the diverse needs of the CF population. Subjects were encouraged but not required to continue the yoga practice at home between sessions.

2.4. Questionnaires. The questionnaires (Cystic Fibrosis Questionnaire-Revised (CFQ-R), Memorial Symptom Assessment Scale (MSAS), Hospital Anxiety and Depression Scale (HADS), Center for Epidemiological Studies-Depression Scale for Children (CES-DC), and the Additional Pain Symptoms Assessment (APSA)) were administered to assess subjects' symptoms of pain, sleep, anxiety, depression, and quality of life immediately before the first session and two weeks after the last session. The Spielberger State-Trait Anxiety Inventory for Children (STAIC) questionnaire was administered before and after each yoga session to assess immediate anxiety reduction. Table 1 describes the timing of questionnaire distribution.

The STAIC is designed to assess both state anxiety, which is how a person feels at the immediate time, and trait anxiety, which describes how likely a person is to react with anxiety to a threatening situation [62]. For this study, we focused on the measure for state anxiety to evaluate a potential change in immediate anxiety levels.

CFQ-R is a disease-specific health-related quality of life questionnaire designed to measure the physical, emotional, and social impact of CF on pediatric patients [63, 64]. The CFQ-R also assesses five subdomains specific to cystic fibrosis: (1) body image, (2) eating disturbances, (3) treatment burden, (4) respiratory symptoms, and (5) digestive symptoms. Three versions of the CFQ-R were used: CFQ- $R$ for ages 6 to 11 years, CFQ-R for ages 12 and 13 years, and CFQ-R for ages 14 to adults [64].

The MSAS assesses multiple symptoms in patients with advanced illnesses. The original tool allows for assessment of 32 symptoms and three dimensions of frequency, severity, and distress. Subscales for analysis include physical distress, psychological distress, and a global distress index [65]. The tool was validated with cancer patients and has been adapted multiple times for use in research with a variety of populations with advanced medical illnesses [66]. A subscale for CF adults was validated for this tool in 2008 with a study that examined symptom prevalence and characteristics in 303 adult patients with CF [67]. Two versions were used for this study: MSAS for ages 7 to 12 and MSAS for ages 10 to 18 $[68,69]$.

The HADS is a validated 14-item instrument that screens for depression and anxiety in children 12 to 18 years of age who have chronic medical conditions. This validated questionnaire has been used extensively in several countries and is available in different languages [70]. The 14 items are divided into subscales for anxiety and depression, both of which were used for this study. CES-DC is a validated 20 -item instrument that evaluates symptoms of depression for ages 12 to 18 [71-73]. This tool was selected in addition to the HADS because it evaluates symptoms of sleep as well as depression.
The CES-DC includes three dimensions: behavior, cognition, and happiness.

The APSA is an unvalidated questionnaire developed at our institution in an effort to thoroughly assess pain symptoms that are not captured in other tools. The survey specifically documents abdominal, chest, limb, and joint pain experienced by subjects in the previous two weeks with the frequency of pain rated on a Likert scale of 1-4 ( $1=$ always, 2 $=$ often, $3=$ sometimes, and $4=$ never) as follows.

Additional Pain Symptoms Assessment. In the past two weeks did you have any of the following:

Abdominal Pain?

$$
\begin{aligned}
& \square \text { Always } \\
& \square \text { Often } \\
& \square \text { Sometimes } \\
& \square \text { Never } \\
& \text { Chest Pain? } \\
& \square \text { Always } \\
& \square \text { Often } \\
& \square \text { Sometimes } \\
& \square \text { Never } \\
& \text { Limb Pain? } \\
& \square \text { Always } \\
& \square \text { Often } \\
& \square \text { Sometimes } \\
& \square \text { Never } \\
& \text { Joint Pain? } \\
& \square \text { Always } \\
& \square \text { Often } \\
& \square \text { Sometimes } \\
& \square \text { Never }
\end{aligned}
$$

All questionnaires were given to subjects based on the age at enrollment. The MSAS, CES-DC, and HADS were completed by subjects over the validated age range, but not by subjects below the validated age range. Table 2 describes the validation age and purpose of each questionnaire.

2.5. Analytic Approach. Median and range (or mean and standard deviation) were used to describe the continuous variables such as mean STAIC score. The nonparametric Wilcoxon Paired Signed Ranks Test was used to compare before and after scores of anxiety, depression, pain, sleep disturbance levels, and quality of life measured by STAIC, CFQR, MSAS, HADS, and CES-DC. A Chi-square test was used to compare the subjects with sleep difficulty before and after yoga sessions. McNemar test was used to compare the binary variables between preintervention and postintervention. All tests employed an alpha level of .05 and were two-sided. We also used the Benjamini-Hochberg Technique (1995) to control the False Discovery Rate across all comparisons in Table 4 [74]. SPSS V15.0 was used to conduct the analyses (SPSS for Windows version 15.0, SPSS Inc., Chicago, IL). 
TABLE 2: Questionnaires: age validation and purpose.

\begin{tabular}{|c|c|c|}
\hline Tools & Validation & Purpose \\
\hline STAIC & $6-17$ years of age & Anxiety \\
\hline STAIC & $18+$ years of age & Anxiety \\
\hline CFQ-R & $\begin{array}{c}6-14+\text { years of } \\
\text { age }\end{array}$ & Quality of life \\
\hline MSAS* & $7-18$ years of age & $\begin{array}{c}\text { Pain and sleep } \\
\text { disturbance }\end{array}$ \\
\hline CES-DC* & $\begin{array}{l}12-18 \text { years of } \\
\text { age }\end{array}$ & Depression \\
\hline HADS ${ }^{*}$ & $\begin{array}{c}12-18 \text { years of } \\
\text { age }\end{array}$ & $\begin{array}{l}\text { Anxiety and } \\
\text { depression }\end{array}$ \\
\hline APSA & Not validated & Pain \\
\hline
\end{tabular}

${ }^{*}$ The MSAS, CES-DC, and HADS were completed by subjects over the validated age range but not by subjects below the validated age range.

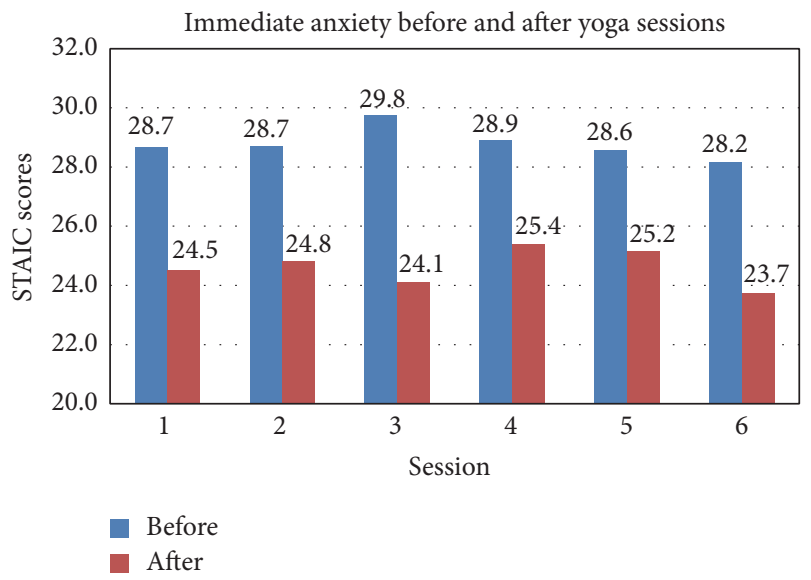

FIGURE 1: STAIC questionnaire: average mean scores for immediate anxiety reduction before and after yoga sessions: all subjects.

\section{Results}

A total of 21 subjects with mild CF lung disease were enrolled in the study. One subject withdrew and 20 subjects completed the study. Analysis included 8 males and 12 females with a mean age of 11 years (range 7 to 20 ) and mean FEV1\%P (forced expiratory volume in 1 second) of $86 \%$. Table 3 describes the study population demographics. Nineteen subjects completed six individual yoga sessions and one completed only five sessions due to a CF related respiratory illness. All sessions were completed within a rolling ten-week timeframe. Table 4 shows all the results with notable findings in bold. Only the STAIC remained significant after adjusting for the false positive rate.

Immediate anxiety improved from before each session (median 29, range 19-39) to after each session (median 23.4, range 20-30) on the STAIC ( $p<0.001$ ) (Figures 1 and 2). Scores for immediate anxiety also improved when comparing before the first session (median 28, range 19-39) to after the last session (median 26, range 20-31, $p=0.024$ ). Sustained anxiety and depression did not show improvement on the CES-DC or HADS.

The CFQ-R showed no notable improvements in quality of life. The domains emotion from before (median 79.2, range 33.3-100) to after (median 85, range 33.3-95.8) yoga intervention $(p=0.073)$ and respiratory before (median 66.7, range 38.9-100) to after (median 79.2, range 38.9-100) yoga intervention $(p=0.076)$ trended towards significance. There were no notable findings for social impact, physical, eating disturbances, body image, social impact, treatment burden, and digestive symptoms.

Pain was evaluated by the MSAS and the APSA. The MSAS showed no notable improvement in self-reported pain. Forty-five percent $(n=9)$ of subjects experienced pain before intervention compared to $35 \%$ after $(n=7, p=0.625)$. The APSA showed an improvement in joint pain from a mean score of 3.25 before intervention to 3.65 after intervention on a scale of 1 to 4 with 3 indicating sometimes having joint pain and 4 indicating never having joint pain $(p=0.028)$.

The MSAS showed no notable changes in sleep disturbance with $25 \%(n=5)$ of subjects reporting difficulty sleeping before intervention compared to $15 \%$ after $(n=3$, $p=0.687$ ). The domain for sleep difficulty before (median 0 , range $0-3$ ) to after (median 0 , range $0-1$ ) yoga intervention trended towards significance $(p=0.088)$.

There was one adverse event of respiratory illness reported during the study, which was not considered related to the yoga therapy/intervention.

\section{Discussion}

Recent advances in the diagnosis and treatment of CF including universal newborn screening and preventive treatments for complications have led to dramatic improvements in lifespan. As life expectancy improves, researchers are evaluating secondary sequelae including pain, sleep disturbance, anxiety, depression, and decreased quality of life that cause psychological distress [10]. This burden is significant in this patient population and we aimed to assess if therapeutic yoga might help alleviate some of these effects.

A previous study in our center assessing symptoms among 39 subjects with CF, ages 7 to 18 years, found that $72 \%$ of subjects experienced depression, $16 \%$ expressed problems with sleep, 37\% experienced moderate to severe long-term anxiety, and $29 \%$ complained of pain (abdomen, chest, limbs, and joints) [11]. A similar study evaluating pain in a group of 46 subjects with CF, ages 8 to 18 years, found that $50 \%$ of subjects experienced stomach pain, $37 \%$ chest pain, and $33 \%$ head pain [7].

After systematic review [75, 76] we found only one prior study performed by Ruddy et al. to evaluate yoga as a complementary therapeutic practice in children with cystic fibrosis [76]. The study presented here is the largest to date and the first with a primary aim is to evaluate therapeutic benefit; however, this is a pilot study and the results should be considered suggestive but not conclusive. The other study was a prospective pilot study conducted primarily to evaluate the safety of a standardized yoga program for patients with cystic fibrosis. The mean (SD) CFQ-R respiratory domain 

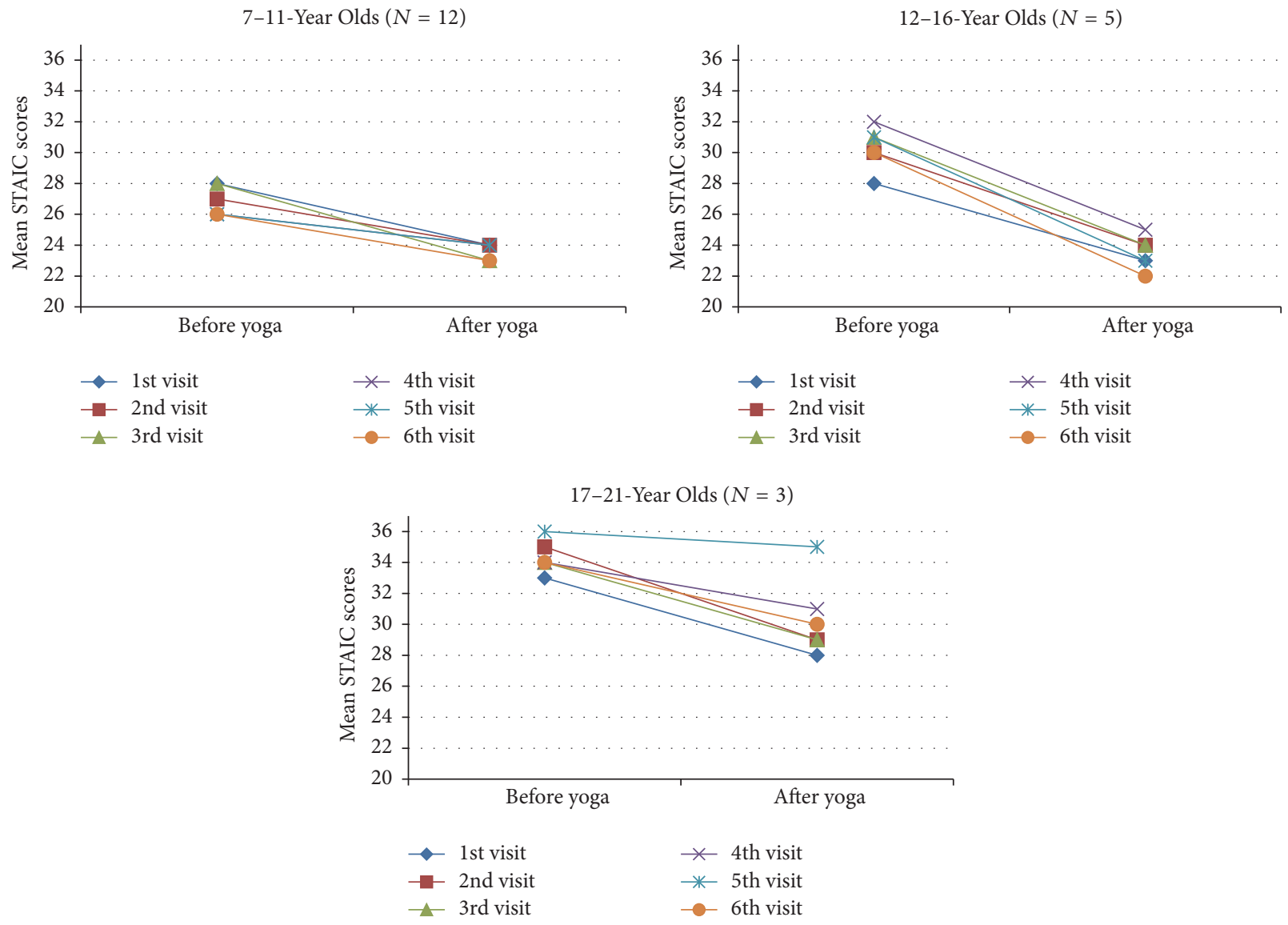

FIGURE 2: STAIC questionnaire: average mean scores for immediate anxiety reduction before and after yoga sessions: by age groups.

TABle 3: Demographics Data.

\begin{tabular}{|c|c|c|c|c|c|}
\hline Study ID & Gender & Ethnicity & Age & Baseline FEV1\% $\mathrm{P}^{*}$ & Lung disease Severity $^{* *}$ \\
\hline 001 & $\mathrm{~F}$ & Caucasian & 14.7 & $86 \%$ & Normal \\
\hline 002 & $\mathrm{~F}$ & Not answered & 13.1 & $116 \%$ & Normal \\
\hline 003 & $\mathrm{~F}$ & Not answered & 14.7 & $71 \%$ & Mild \\
\hline 005 & M & Caucasian & 12.1 & $96 \%$ & Normal \\
\hline 006 & M & Caucasian & 11.9 & $82 \%$ & Normal \\
\hline 007 & $\mathrm{~F}$ & African American & 17.2 & $82 \%$ & Normal \\
\hline 008 & $\mathrm{~F}$ & Caucasian & 9.7 & $57 \%$ & Moderate \\
\hline 009 & M & Caucasian & 9.0 & $83 \%$ & Normal \\
\hline 010 & $\mathrm{~F}$ & Hispanic & 14.0 & $66 \%$ & Mild \\
\hline 011 & M & Caucasian & 11.9 & $95 \%$ & Normal \\
\hline 012 & $\mathrm{~F}$ & Caucasian & 19.5 & $94 \%$ & Normal \\
\hline 013 & $\mathrm{~F}$ & Caucasian & 8.7 & $116 \%$ & Normal \\
\hline 014 & M & Caucasian & 10.0 & $89 \%$ & Normal \\
\hline 015 & M & Caucasian & 7.6 & $102 \%$ & Normal \\
\hline 016 & M & Caucasian & 7.6 & $74 \%$ & Mild \\
\hline 017 & $\mathrm{~F}$ & Caucasian & 19.4 & $74 \%$ & Mild \\
\hline 018 & $\mathrm{~F}$ & Caucasian & 8.9 & $75 \%$ & Mild \\
\hline 019 & F & Caucasian & 7.1 & $52 \%$ & Moderate \\
\hline 020 & $\mathrm{~F}$ & Caucasian & 7.3 & $111 \%$ & Normal \\
\hline 021 & M & Caucasian & 7.3 & $106 \%$ & Normal \\
\hline
\end{tabular}

${ }^{*} \mathrm{FEV} 1 \% \mathrm{P}$ is the forced expiratory volume in 1 second.

${ }^{* *}$ Lung disease severity measured by FEV1\%P: normal is $\geq 80 \%$, mild is $60 \%-79 \%$, moderate is $40-59$, and severe is $\leq 40 \%$. 
TABLE 4: Results of 6 Yoga sessions over a ten-week intervention in children with cystic fibrosis.

\begin{tabular}{|c|c|c|c|c|}
\hline Measure & $N$ & Before intervention & After intervention & $p$ value \\
\hline STAIC, median (range) & 20 & $28(19,39)$ & $26(20,31)$ & $0.024^{*}$ \\
\hline \multicolumn{5}{|l|}{ CFQ-R, median (range) } \\
\hline Emotion & & $79.2(33.3,100)$ & $85(33.3,95.8)$ & 0.073 \\
\hline Physical & & $83.3(54.2,100)$ & $85.4(45.8,100)$ & 0.924 \\
\hline Social impact & & $84.5(47.6,95.2)$ & $76.2(42.9,95.2)$ & 0.393 \\
\hline \multicolumn{5}{|l|}{ CF specific domain } \\
\hline Body image & & $83.3(22.2,100)$ & $88.9(33.3,100)$ & 0.287 \\
\hline Respiratory symptoms & & $66.7(38.9,100)$ & $79.2(38.9,100)$ & 0.076 \\
\hline Digestive symptoms & & $66.7(33.3,100)$ & $72.2(33.3,100)$ & 0.748 \\
\hline Treatment burden & & $55.6(22.2,100)$ & $66.7(0,100)$ & 0.629 \\
\hline Eating disturbances & 20 & $94.4(22.2,100)$ & $88.9(22.2,100)$ & 0.721 \\
\hline \multicolumn{5}{|l|}{ MSAS } \\
\hline Pain, $n(\%)$ & & $9(45)$ & $7(35)$ & 0.625 \\
\hline Sleep difficulty, $n(\%)$ & & $5(25)$ & $3(15)$ & 0.687 \\
\hline Sleep difficulty, median (range) & 20 & $0(0,3)$ & $0(0,1)$ & 0.088 \\
\hline \multicolumn{5}{|l|}{ HADS, median (range) } \\
\hline Anxiety & & $8.5(0,15)$ & $9(1,15)$ & 0.497 \\
\hline Depression & 10 & $6.5(0,12)$ & $8(0,12)$ & 0.491 \\
\hline CES-DC, median (range) & 10 & $16.5(0,28)$ & $16(10,42)$ & 0.141 \\
\hline \multicolumn{5}{|l|}{ APSA } \\
\hline Abdominal pain, median (range) & & $4(1,4)$ & $3.5(1,4)$ & 0.564 \\
\hline Chest pain, median (range) & & $4(3,4)$ & $4(2,4)$ & 0.480 \\
\hline Limb pain, median (range) & & $4(2,4)$ & $4(2,4)$ & 0.248 \\
\hline Joint pain, median (range) & & $4(1,4)$ & $4(2,4)$ & $0.033^{*}$ \\
\hline \multirow[t]{2}{*}{ Joint pain, mean (95\% CI) } & 20 & $3.3(2.8,3.7)$ & $3.7(3.4,3.9)$ & $0.028^{*}$ \\
\hline & & Before each session & After each session & \\
\hline STAIC, median (range) & 20 & $29.1(19,39)$ & $23.4(20,30)$ & $<0.001^{* *}$ \\
\hline
\end{tabular}

${ }^{*}$ Significantly different at $\alpha=0.05$.

** Significantly different at $\alpha=0.05$ adjusting for 18 comparisons (only STAIC remained significant after adjustment for multiple variables).

STAIC: immediate anxiety. Total score ranging from 0 to 60 , lower score is better.

CFQ-R: scaled score between 0 and 100 , higher is better.

MSAS: scaled score between $0-4$ for each domain, lower is better.

HADS: scaled score between 0 and 21, lower is better.

CES-DC: scaled score between 0 and 60 , lower is better.

APSA: scale of 1 to 4 , higher is better.

score increased significantly from screening to end of study, 67.9 (11.40 to $82.1(9.9)),(p=0.04)$ in the 10 participants who completed the program. No other outcome measures reached significance and it was recommended that further testing with larger trials be conducted [76]. Twenty participants completed the yoga program offered at our site. As with Ruddy et al. [76], the subjects in our study tolerated the yoga therapy safely.

Our most notable finding was an improvement in immediate anxiety from before each yoga therapy session (median 29 , range 19-39) to after (median 23.4, range 20-30) on the STAIC $(p<0.001)$. Prior to study participation immediate anxiety levels for the study population were within normal limits when compared to the general population for this age group. However, STAIC scores trended towards improvement from immediately before a single yoga session to immediately after a session as shown in Figure 1. Additionally, the first questionnaire completed at enrollment compared to the last questionnaire at the follow-up visit showed a significant decrease in immediate anxiety $(p=0.024)$. Increased anxiety levels may impair attention and disrupt cognitive information processing [77], so an intervention that is able to reduce immediate anxiety may provide real benefit. One subject expressed how, when feeling anxious at school, she practiced a breathing technique that she learned from her yoga instructor and found the method to be helpful. Unfortunately, we were not able to show any notable improvement in sustained anxiety or depression.

The APSA showed a notable improvement in reported joint pain from prior to initiating yoga therapy to after the conclusion of yoga sessions $(p=0.028)$. The MSAS, a tool that measures more generalized self-reported pain, decreased from $45 \%$ of subjects experiencing pain before treatment to $35 \%$ after but, with the admitted limitation of our small 
sample size, was not notable $(p=0.625)$. Pain is significant in patients with $\mathrm{CF}[7,11]$ and it is a symptom that people with CF of all ages experience with an increase in severity and duration with age, unrelated to disease severity $[77,78]$. Yoga may be helpful for managing at least some of these pain symptoms. Beginning the practice and lifestyle of yoga early in life may provide larger benefits later in life.

The CFQ-R emotion subscale, which addressed feelings of worry, loneliness, sadness, and the desire to make future plans, did not show notable improvements $(p=0.073)$. The respiratory subscale also did not show notable improvements ( $p=0.076)$ in our study. It is worth noting that the Ruddy et al. study did show a significant improvement in the CFQ$\mathrm{R}$ respiratory subscale in their ten-participant cohort $(p=$ 0.04 ) with a more intense session period (twice a week for 10 weeks), but they were also unable to show significant improvement in the emotion subscale $(p=0.13)$ The Ruddy et al. protocol was to practice yoga twice a week for 8 weeks and had a mean attendance of 14 sessions [76]. Larger controlled trials may be warranted to further investigate yoga and quality of life improvements in patients with $\mathrm{CF}$, especially since yoga has been shown to increase quality of life scores in other chronic disease populations including breast cancer, rheumatoid arthritis, and children with hemophilia $[40,42,51]$ as well as respiratory diseases such as asthma [79].

The study presented here did not show notable improvement in sleep difficulties with yoga therapy but did demonstrate a trend towards significance in sleep difficulty before (median 0 , range $0-3$ ) to after (median 0 , range $0-1$ ) yoga intervention $(p=0.088)$. The prevalence of sleep difficulties is well documented in the CF population $[8,11-19]$ with possible etiologies including nocturnal hypoxemia preventing REM sleep $[12,13]$ and nocturnal cough.

4.1. Limitations. Our study demonstrated two promising and notable outcomes of reduction in pain and immediate anxiety which suggest a trend towards improvement despite the low power of our 20-participant cohort. Demonstrating significance in this small, healthier CF cohort may have been a limitation since our population has excellent pulmonary outcomes overall. Thus, a lower pain prevalence and symptomatic burden within our population is expected. This study lacked a control group, which may have strengthened our findings. We did not assess the duration of the short-term anxiety relief experienced. While this study demonstrated an immediate improvement in anxiety, we do not know if this relief lasts minutes, hours, or days. To this end, questionnaires assessing general anxiety administered during the yoga therapy period would be of interest. We did not have a validated tool for patients with CF to assess localized pain such as limb and joint.

Our study was limited by the small number of yoga sessions: 6 sessions over 10 weeks for 19 participants and 5 sessions for 1 participant. It is possible that the intensity and duration of the yoga therapy in our study were too small, with too few yoga sessions spread too far apart over too short a time. Larger studies with an objective measurement of sleep quality, such as with sleep actigraphy, during an experimental yoga therapy trial may be beneficial.

\section{Conclusions}

This yoga session interventional pilot study for patients with CF demonstrated a notable decrease in immediate anxiety from prior to and just after yoga therapy sessions. This study also showed a notable decrease in reported joint pain from before the trial of yoga therapy began to after it was completed. Yoga as a complementary therapy may be a valuable option for patients with CF who are experiencing pain or anxiety related to their health, school, or social activities. Our results are consistent with the literature that yoga is safe and well tolerated in children and adolescents with mild to moderate lung disease. Our findings of notable improvements in a small pilot study with a relatively low dose of yoga therapy and other measures trending towards significance suggest that larger controlled trials conducted to determine the benefits of yoga for patients with CF would be valuable.

\section{Competing Interests}

No competing financial interests exist.

\section{Acknowledgments}

The authors thank Children's Respiratory and Critical Care Specialists, PA, and the certified yoga instructors who worked on this study: Anne Murphy, Laurie Foster, Michelle Wagner, and Nissa Valdez. The authors would also like to thank the University of Minnesota CF Program for referring patients for this study opportunity. A poster was presented at the 2011 North American Cystic Fibrosis Conference at the Anaheim Convention Center, Anaheim, California.

\section{References}

[1] G. S. Sawicki, L. R. Rasouliyan, A. H. McMullen et al., "Longitudinal assessment of health-related quality of life in an observational cohort of patients with cystic fibrosis," Pediatric Pulmonology, vol. 46, no. 1, pp. 36-44, 2011.

[2] S. D. Strausbaugh and P. B. Davis, "Cystic fibrosis: a review of epidemiology and pathobiology," Clinics in Chest Medicine, vol. 28, no. 2, pp. 279-288, 2007.

[3] A. L. Quittner, A. N. Alpern, and L. S. Blackwell, "Treatment adherence in adolescents with cystic fibrosis," in Health Care Issues and Challenges in the Adolescent with Cystic Fibrosis, C. Castellani, S. Elborn, and H. Heijerman, Eds., pp. 77-79, Elsevier, Oxford, UK, 2012.

[4] A. L. Quittner, L. Goldbeck, J. Abbott et al., "Prevalence of depression and anxiety in patients with cystic fibrosis and parent caregivers: results of the International Depression Epidemiological Study across nine countries," Thorax, vol. 69, no. 12, pp. 1090-1097, 2014.

[5] E. T. Zemanick, J. K. Harris, S. Conway et al., "Measuring and improving respiratory outcomes in cystic fibrosis lung disease: opportunities and challenges to therapy," Journal of Cystic Fibrosis, vol. 9, no. 1, pp. 1-16, 2010.

[6] J. Abbott, M. A. Hurley, A. M. Morton, and S. P. Conway, "Longitudinal association between lung function and healthrelated quality of life in cystic fibrosis," Thorax, vol. 68 , no. 2 , pp. 149-154, 2013. 
[7] J. L. Koh, D. Harrison, T. M. Palermo, H. Turner, and T. McGraw, "Assessment of acute and chronic pain symptoms in children with cystic fibrosis," Pediatric Pulmonology, vol. 40, no. 4, pp. 330-335, 2005.

[8] L. Jankelowitz, K. J. Reid, L. Wolfe, J. Cullina, P. C. Zee, and M. Jain, "Cystic fibrosis patients have poor sleep quality despite normal sleep latency and efficiency," Chest, vol. 127, no. 5, pp. 1593-1599, 2005.

[9] T. Havermans, K. Colpaert, and L. J. Dupont, "Quality of life in patients with cystic fibrosis: association with anxiety and depression," Journal of Cystic Fibrosis, vol. 7, no. 6, pp. 581-584, 2008.

[10] A. L. Quittner, E. Saez-Flores, and J. D. Barton, "The psychological burden of cystic fibrosis," Current Opinion in Pulmonary Medicine, vol. 22, no. 2, pp. 187-191, 2016.

[11] S. O'Conner-Von, L. Johnson, and E. Leighton, "Symptom profile of pediatric patients with cystic fibrosis: body image, pain, sleep, and depression," Pediatric Pulmonology, supplement 32, p. 594, 2009.

[12] M. P. Villa, J. Pagani, V. Lucidi, S. Palamides, and R. Ronchetti, "Nocturnal oximetry in infants with cystic fibrosis," Archives of Disease in Childhood, vol. 84, no. 1, pp. 50-54, 2001.

[13] L. Van Der Giessen, M. Loeve, J. De Jongste, W. Hop, and H. Tiddens, "Nocturnal cough in children with stable cystic fibrosis," Pediatric Pulmonology, vol. 44, no. 9, pp. 859-865, 2009.

[14] S. K. Naqvi, C. Sotelo, L. Murry, and N. Simakajornboon, "Sleep architecture in children and adolescents with cystic fibrosis and the association with severity of lung disease," Sleep and Breathing, vol. 12, no. 1, pp. 77-83, 2008.

[15] D. R. Dancey, E. D. Tullis, R. Heslegrave, K. Thornley, and P. J. Hanly, "Sleep quality and daytime function in adults with cystic fibrosis and severe lung disease," European Respiratory Journal, vol. 19, no. 3, pp. 504-510, 2002.

[16] R. T. T. Ramos, C. Salles, C. H. C. Daltro, M. A. Santana, P. B. Gregório, and A. X. Acosta, "Sleep architecture and polysomnographic respiratory profile of children and adolescents with cystic fibrosis," Jornal de Pediatria, vol. 87, no. 1, pp. 63-69, 2011.

[17] B. Fauroux, J.-L. Pepin, P.-Y. Boelle et al., "Sleep quality and nocturnal hypoxaemia and hypercapnia in children and young adults with cystic fibrosis," Archives of Disease in Childhood, vol. 97, no. 11, pp. 960-966, 2012.

[18] S. M. Paranjape, B. M. McGinley, A. T. Braun, and H. Schneider, "Polysomnographic markers in children with cystic fibrosis lung disease," Pediatrics, vol. 136, no. 5, pp. 920-926, 2015.

[19] K. Cavanaugh, L. Read, J. Dreyfus, M. Johnson, and J. McNamara, "Association of poor sleep with behavior and quality of life in children and adolescents with cystic fibrosis," Sleep and Biological Rhythms, vol. 14, no. 2, pp. 199-204, 2016.

[20] D. W. Beebe, M. D. Ris, M. E. Kramer, E. Long, and R. Amin, "The association between sleep disordered breathing, academic grades, and cognitive and behavioral functioning among overweight subjects during middle to late childhood," Sleep, vol. 33, no. 11, pp. 1447-1456, 2010.

[21] B. H. Hansen, B. Skirbekk, B. Oerbeck, T. Wentzel-Larsen, and $\mathrm{H}$. Kristensen, "Associations between sleep problems and attentional and behavioral functioning in children with anxiety disorders and ADHD," Behavioral Sleep Medicine, vol. 12, no. 1, pp. 53-68, 2014.

[22] R. Amin, J. Bean, K. Burklow, and J. Jeffries, “The relationship between sleep disturbance and pulmonary function in stable pediatric cystic fibrosis patients," Chest, vol. 128, no. 3, pp. 1357$1363,2005$.

[23] M. Pinquart and Y. Shen, "Depressive symptoms in children and adolescents with chronic physical illness: an updated metaanalysis," Journal of Pediatric Psychology, vol. 36, no. 4, pp. 375384, 2011.

[24] K. R. Fauman, K. J. Pituch, Y. Y. Han, M. F. Niedner, J. Reske, and A. M. Levine, "Predictors of depressive symptoms in parents of chronically ill children admitted to the pediatric intensive care unit," American Journal of Hospice and Palliative Care, vol. 28, no. 8, pp. 556-563, 2011.

[25] S. Moussavi, S. Chatterji, E. Verdes, A. Tandon, V. Patel, and B. Ustun, "Depression, chronic diseases, and decrements in health: results from the World Health Surveys," Lancet, vol. 370, no. 9590, pp. 851-858, 2007.

[26] J. L. Grenard, B. A. Munjas, J. L. Adams et al., "Depression and medication adherence in the treatment of chronic diseases in the United States: a meta-analysis," Journal of General Internal Medicine, vol. 26, no. 10, pp. 1175-1182, 2011.

[27] M. E. Hilliard, M. N. Eakin, B. Borrelli, A. Green, and K. A. Riekert, "Medication beliefs mediate between depressive symptoms and medication adherence in cystic fibrosis," Health Psychology, vol. 34, no. 5, pp. 496-504, 2015.

[28] A. Tanase and R. Zanni, "The use of complementary and alternative medicine among pediatric cystic fibrosis patients," Journal of Alternative and Complementary Medicine, vol. 14, no. 10, pp. 1271-1273, 2008.

[29] P. E. Jeter, J. Slutsky, N. Singh, and S. B. S. Khalsa, "Yoga as a therapeutic intervention: a bibliometric analysis of published research studies from 1967 to 2013," Journal of Alternative and Complementary Medicine, vol. 21, no. 10, pp. 586-592, 2015.

[30] O. Parshad, "Role of yoga in stress management," West Indian Medical Journal, vol. 53, no. 3, pp. 191-194, 2004.

[31] A. E. Holland, C. J. Hill, A. Y. Jones, and C. F. McDonald, "Breathing exercises for chronic obstructive pulmonary disease," The Cochrane Database of Systematic Reviews, vol. 10, Article ID CD008250, 2012.

[32] S. Holtzman and R. T. Beggs, "Yoga for chronic low back pain: a meta-analysis of randomized controlled trials," Pain Research and Management, vol. 18, no. 5, pp. 267-272, 2013.

[33] K. Yang, L. M. Bernardo, S. M. Sereika, M. B. Conroy, J. Balk, and L. E. Burke, "Utilization of 3-month yoga program for adults at high risk for type 2 diabetes: A Pilot Study," Evidencebased Complementary and Alternative Medicine, vol. 2011, Article ID 257891, 6 pages, 2011.

[34] H. Cramer, R. Lauche, J. Langhorst, and G. Dobos, "Yoga for depression: a systematic review and meta-analysis," Depression and Anxiety, vol. 30, no. 11, pp. 1068-1083, 2013.

[35] H. Cramer, R. Lauche, H. Haller, N. Steckhan, A. Michalsen, and G. Dobos, "Effects of yoga on cardiovascular disease risk factors: a systematic review and meta-analysis," International Journal of Cardiology, vol. 173, no. 2, pp. 170-183, 2014.

[36] G. S. Birdee, R. L. Rothman, S. J. Sohl et al., "Feasibility and safety of intradialysis yoga and education in maintenance hemodialysis patients," Journal of Renal Nutrition, vol. 25, no. 5, pp. 445-453, 2015.

[37] S. Evans, L. Seidman, B. Sternlieb, J. Casillas, L. Zeltzer, and J. Tsao, "Clinical case report: yoga for fatigue in five young adult survivors of childhood cancer," Journal of Adolescent and Young Adult Oncology, 2016. 
[38] N. Brondino, L. Fusar-Poli, M. Rocchetti, U. Provenzani, F. Barale, and P. Politi, "Complementary and alternative therapies for autism spectrum disorder," Evidence-based Complementary and Alternative Medicine, vol. 2015, Article ID 258589, 31 pages, 2015.

[39] B. Pradhan, T. Parikh, R. Makani, and M. Sahoo, "Ketamine, transcranial magnetic stimulation, and depression specific yoga and mindfulness based cognitive therapy in management of treatment resistant depression: review and some data on efficacy," Depression Research and Treatment, vol. 2015, Article ID 842817, 14 pages, 2015.

[40] D. Lötzke, F. Wiedemann, D. Rodrigues Recchia et al., "IyengarYoga compared to exercise as a therapeutic Intervention during (Neo)adjuvant therapy in women with stage I-III breast cancer: health-related quality of life, mindfulness, spirituality, life satisfaction, and cancer-related fatigue," Evidence-Based Complementary and Alternative Medicine, vol. 2016, Article ID 5931816, 8 pages, 2016.

[41] R. Gokal, L. Shillito, and S. R. Maharaj, "Positive impact of yoga and pranayam on obesity, hypertension, blood sugar, and cholesterol: a pilot assessment," Journal of Alternative and Complementary Medicine, vol. 13, no. 10, pp. 1056-1057, 2007.

[42] N. Beheshtipoor, S. Bagheri, F. Hashemi, N. Zare, and M. Karimi, "The effect of yoga on the quality of life in the children and adolescents with haemophilia," International Journal of Community Based Nursing and Midwifery, vol. 3, no. 2, pp. 150155, 2015.

[43] C. Diorio, T. Schechter, M. Lee et al., "A pilot study to evaluate the feasibility of individualized yoga for inpatient children receiving intensive chemotherapy," BMC Complementary and Alternative Medicine, vol. 15, no. 1, article 2, 2015.

[44] S. Evans, K. C. Lung, L. C. Seidman, B. Sternlieb, L. K. Zeltzer, and J. C. I. Tsao, "Iyengar yoga for adolescents and young adults with irritable bowel syndrome," Journal of Pediatric Gastroenterology and Nutrition, vol. 59, no. 2, pp. 244-253, 2014.

[45] J. J. Korterink, L. E. Ockeloen, M. Hilbink, M. A. Benninga, and J. M. Deckers-kocken, "Yoga therapy for abdominal pain related-functional gastrointestinal disorders in children. A randomized controlled trial," Journal of Pediatric Gastroenterology and Nutrition, vol. 63, no. 5, pp. 481-487, 2016.

[46] J. C. Sieverdes, M. Mueller, M. J. Gregoski et al., "Effects of hatha yoga on blood pressure, salivary $\alpha$-amylase, and cortisol function among normotensive and prehypertensive youth," Journal of Alternative and Complementary Medicine, vol. 20, no. 4, pp. 241-250, 2014.

[47] A. Woolery, H. Myers, B. Sternlieb, and L. Zeltzer, "A yoga intervention for young adults with elevated symptoms of depression," Alternative Therapies in Health and Medicine, vol. 10, no. 2, pp. 60-63, 2004.

[48] L. Kuttner, C. T. Chambers, J. Hardial, D. M. Israel, K. Jacobson, and K. Evans, "A randomized trial of yoga for adolescents with irritable bowel syndrome," Pain Research and Management, vol. 11, no. 4, pp. 217-224, 2006.

[49] A. M. Ben-Josef, E. P. Wileyto, J. Chen, and N. Vapiwala, "Yoga intervention for patients with prostate cancer undergoing external beam radiation therapy: A Pilot Feasibility Study," Integrative Cancer Therapies, vol. 15, no. 3, pp. 272-278, 2016.

[50] M. S. Rosenbaum and J. Velde, "The effects of yoga, massage, and reiki on patient well-being at a cancer resource center," Clinical Journal of Oncology Nursing, vol. 20, no. 3, pp. E77-E81, 2016.
[51] S. Evans, M. Moieni, K. Lung et al., "Impact of iyengar yoga on quality of life in young women with rheumatoid arthritis," Clinical Journal of Pain, vol. 29, no. 11, pp. 988-997, 2013.

[52] A. A. Schmid, E. Debaun-Sprague, A. M. Gilles et al., "Yoga influences recovery during inpatient rehabilitation: a pilot study," International Journal of Yoga Therapy, vol. 25, no. 1, pp. 141-152, 2015.

[53] C. Cheung, J. Park, and J. F. Wyman, "Effects of yoga on symptoms, physical function, and psychosocial outcomes in adults with osteoarthritis: a focused review," American Journal of Physical Medicine \& Rehabilitation, vol. 95, no. 2, pp. 139-151, 2016.

[54] K. Boehm, T. Ostermann, S. Milazzo, and A. Büssing, "Effects of yoga interventions on fatigue: a meta-analysis," Evidence-Based Complementary and Alternative Medicine, vol. 2012, Article ID 124703, 9 pages, 2012.

[55] S. Telles, K. V. Naveen, V. Gaur, and A. Balkrishna, "Effect of one week of yoga on function and severity in rheumatoid arthritis," BMC Research Notes, vol. 4, article 118, 2011.

[56] I. Farver-Vestergaard, D. Jacobsen, and R. Zachariae, "Efficacy of psychosocial interventions on psychological and physical health outcomes in chronic obstructive pulmonary disease: a systematic review and meta-analysis," Psychotherapy and Psychosomatics, vol. 84, no. 1, pp. 37-50, 2015.

[57] H. Cramer, P. Posadzki, G. Dobos, and J. Langhorst, "Yoga for asthma: a systematic review and meta-analysis," Annals of Allergy, Asthma and Immunology, vol. 112, no. 6, pp. 503-510.e5, 2014.

[58] R. Vempati, R. L. Bijlani, and K. K. Deepak, "The efficacy of a comprehensive lifestyle modification programme based on yoga in the management of bronchial asthma: a randomized controlled trial," BMC Pulmonary Medicine, vol. 9, article 37, 2009.

[59] S. C. Jain, L. Rai, A. Valecha, U. K. Jha, S. O. D. Bhatnagar, and K. Ram, "Effect of yoga training on exercise tolerance in adolescents with childhood asthma," Journal of Asthma, vol. 28, no. 6, pp. 437-442, 1991.

[60] S. Singh, R. Soni, K. P. Singh, and O. P. Tandon, "Effect of yoga practices on pulmonary function tests including transfer factor of lung for carbon monoxide (TLCO) in asthma patients," Indian Journal of Physiology and Pharmacology, vol. 56, no. 1, pp. 63-68, 2012.

[61] Z. Y. Yang, H. B. Zhong, C. Mao et al., "Yoga for asthma," The Cochrane Database of Systematic Reviews, vol. 4, Article ID CD010346, 2016.

[62] C. Spielberger, C. Edwards, J. Montuori, and R. Lushene, HowI-Feel Questionnaire, Mind Garden, 1970.

[63] A. Quittner, A. Buu, M. Watrous, and M. Davis, The Cystic Fibrosis Questionnaire (CFQ) User's Manual, Cystic Fibrosis Foundation, Washington, DC, USA, 2000.

[64] A. C. Modi and A. L. Quittner, "Validation of a disease-specific measure of health-related quality of life for children with cystic fibrosis," Journal of Pediatric Psychology, vol. 28, no. 8, pp. 535545, 2003.

[65] R. K. Portenoy, H. T. Thaler, A. B. Kornblith et al., "The Memorial Symptom Assessment Scale: an instrument for the evaluation of symptom prevalence, characteristics and distress," European Journal of Cancer, vol. 30, no. 9, pp. 1326-1336, 1994.

[66] V. T. Chang, S. S. Hwang, H. T. Thaler, B. S. Kasimis, and R. K. Portenoy, "Memorial symptom assessment scale," Expert Review of Pharmacoeconomics and Outcomes Research, vol. 4, no. 2, pp. 171-178, 2004. 
[67] G. S. Sawicki, D. E. Sellers, and W. M. Robinson, "Self-reported physical and psychological symptom burden in adults with cystic fibrosis," Journal of Pain and Symptom Management, vol. 35, no. 4, pp. 372-380, 2008.

[68] J. J. Collins, M. E. Byrnes, I. J. Dunkel et al., "The measurement of symptoms in children with cancer," Journal of Pain and Symptom Management, vol. 19, no. 5, pp. 363-377, 2000.

[69] J. J. Collins, T. D. Devine, G. S. Dick et al., "The measurement of symptoms in young children with cancer: the validation of the memorial symptom assessment scale in children aged 7-12," Journal of Pain and Symptom Management, vol. 23, no. 1, pp. 1016, 2002.

[70] I. Bjelland, A. A. Dahl, T. T. Haug, and D. Neckelmann, “The validity of the hospital anxiety and depression scale: an updated literature review," Journal of Psychosomatic Research, vol. 52, no. 2, pp. 69-77, 2002.

[71] M. M. Weissman, H. Orvaschel, and N. Padian, "Children's symptom and social functioning self-report scales. Comparison of mothers' and children's reports," Journal of Nervous and Mental Disease, vol. 168, no. 12, pp. 736-740, 1980.

[72] M. Fendrich, M. M. Weissman, and V. Warner, "Screening for depressive disorder in children and adolescents: validating the Center for Epidemiologic Studies Depression Scale for children," American Journal of Epidemiology, vol. 131, no. 3, pp. 538-551, 1990.

[73] M. E. Faulstich, M. P. Carey, L. Ruggiero, P. Enyart, and F. Gresham, "Assessment of depression in childhood and adolescence: an evaluation of the center for epidemiological studies depression scale for children (CES-DC)," American Journal of Psychiatry, vol. 143, no. 8, pp. 1024-1027, 1986.

[74] Y. Benjamini and Y. Hochberg, "Controlling the false discovery rate: a practical and powerful approach to multiple testing," Journal of the Royal Statistical Society. Series B. Methodological, vol. 57, no. 1, pp. 289-300, 1995.

[75] A. B. Lorenc, Y. Wang, S. L. Madge, X. Hu, A. M. Mian, and N. Robinson, "Meditative movement for respiratory function: a systematic review," Respiratory Care, vol. 59, no. 3, pp. 427-440, 2014.

[76] J. Ruddy, J. Emerson, S. McNamara et al., "Yoga as a therapy for adolescents and young adults with cystic fibrosis: a pilot study," Global Advances in Health and Medicine, vol. 4, no. 6, pp. 32-36, 2015.

[77] R. J. Semple, J. Lee, D. Rosa, and L. F. Miller, "A randomized trial of mindfulness-based cognitive therapy for children: promoting mindful attention to enhance social-emotional resiliency in children," Journal of Child and Family Studies, vol. 19, no. 2, pp. 218-229, 2010.

[78] I. Sermet-Gaudelus, P. De Villartay, P. de Dreuzy et al., "Pain in children and adults with cystic fibrosis: a comparative study," Journal of Pain and Symptom Management, vol. 38, no. 2, pp. 281-290, 2009.

[79] A. J. Bidwell, B. Yazel, D. Davin, T. J. Fairchild, and J. A. Kanaley, "Yoga training improves quality of life in women with asthma," The Journal of Alternative and Complementary Medicine, vol. 18, no. 8, pp. 749-755, 2012. 


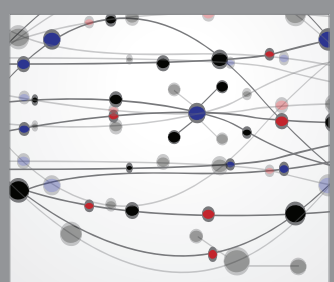

The Scientific World Journal
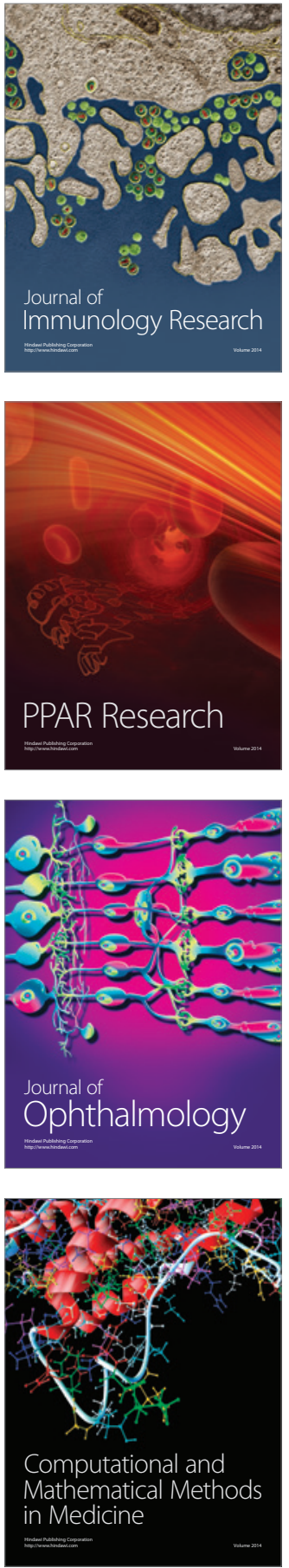

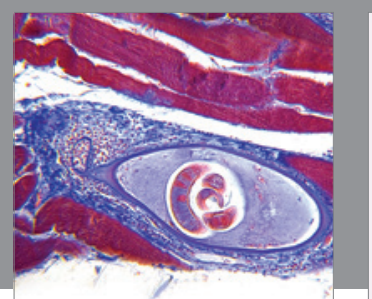

Gastroenterology Research and Practice

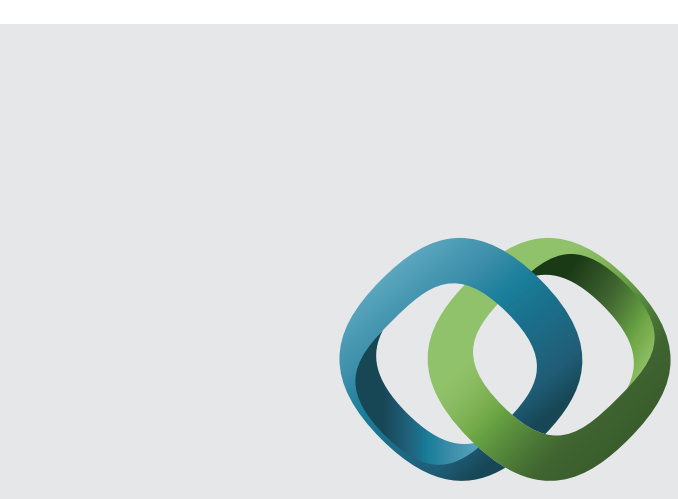

\section{Hindawi}

Submit your manuscripts at

http://www.hindawi.com
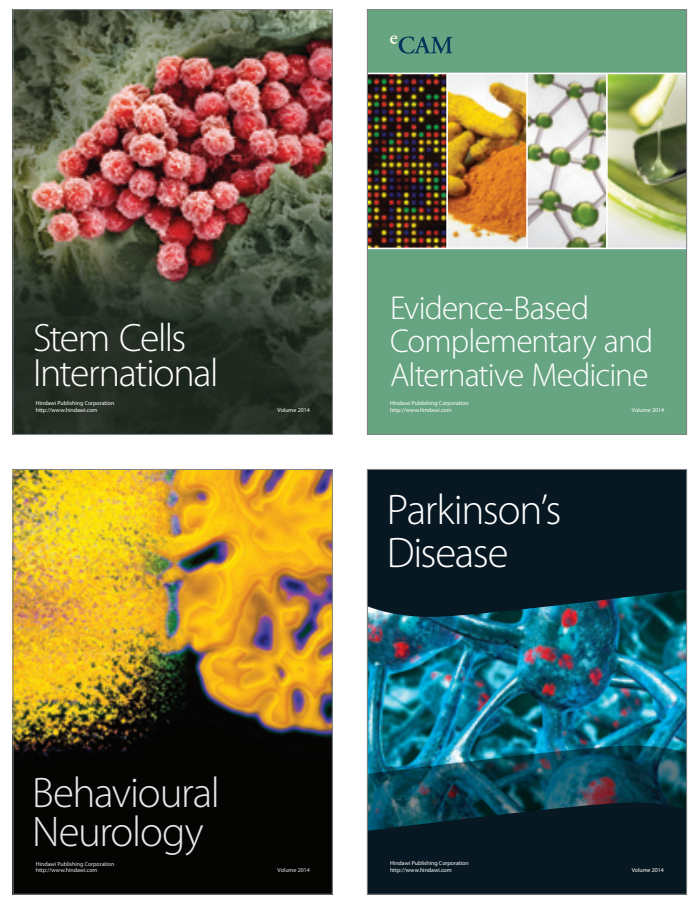
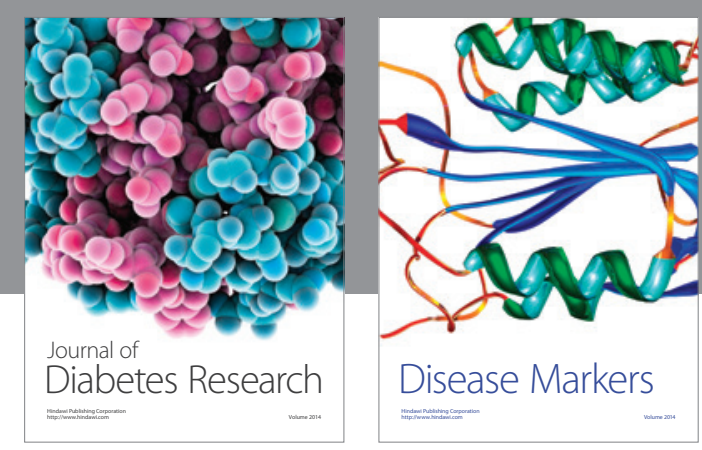

Disease Markers
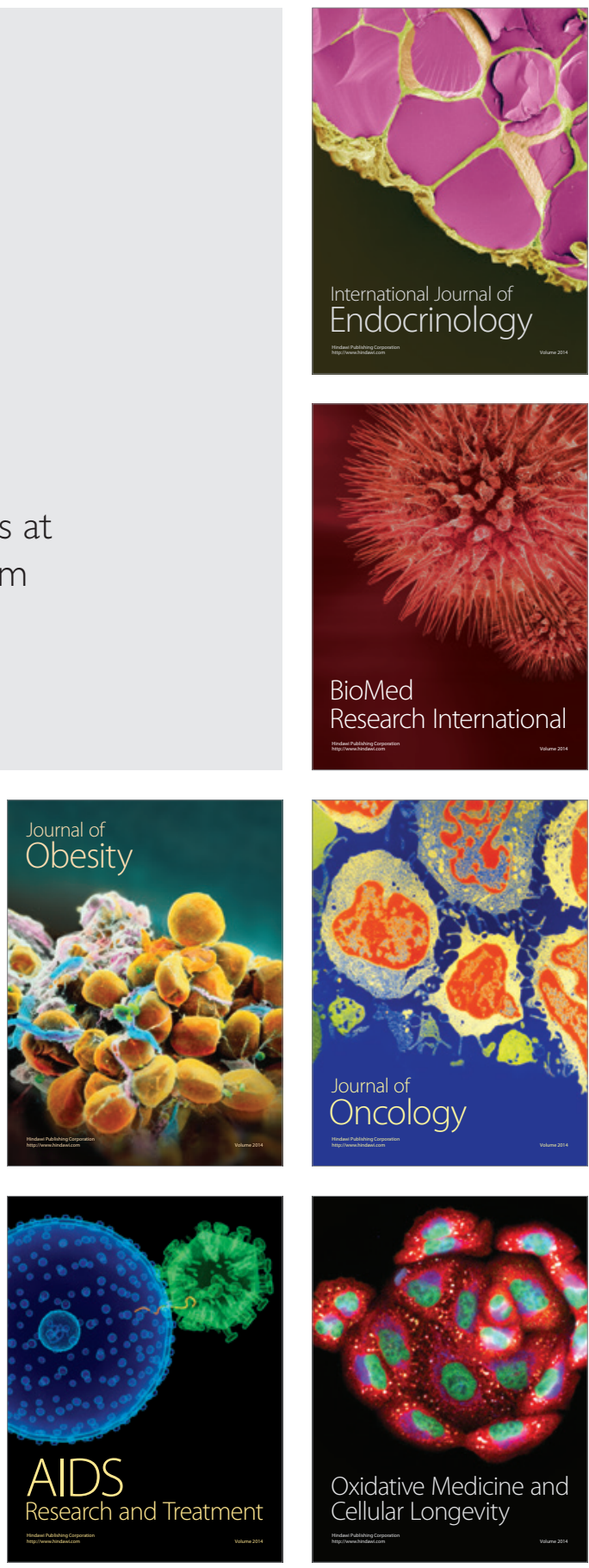